\title{
Pricing Chinese Convertible Bonds with Default Intensity by Monte Carlo Method
}

\author{
Xin Luo $\mathbb{D}^{1,2}$ and Jinlin Zhang ${ }^{1}$ \\ ${ }^{1}$ School of Finance, Zhongnan University of Economics and Law, Wuhan, China \\ ${ }^{2}$ College of Economics and Management, Hubei University of Automotive Technology, Shiyan, China
}

Correspondence should be addressed to Xin Luo; xinluo@zuel.edu.cn

Received 18 December 2018; Accepted 28 March 2019; Published 15 April 2019

Academic Editor: Paolo Renna

Copyright ( 2019 Xin Luo and Jinlin Zhang. This is an open access article distributed under the Creative Commons Attribution License, which permits unrestricted use, distribution, and reproduction in any medium, provided the original work is properly cited.

\begin{abstract}
This article proposes a new way to price Chinese convertible bonds by the Longstaff-Schwartz Least Squares Monte Carlo simulation. The default intensity and the volatility are the two important parameters, which are difficultly obtained in the emerging market, in pricing convertible bonds. By developing the Merton theory, we find a new effective method to get the theoretical value of the two parameters. In the pricing method, the default risk is described by the default intensity, and a default on a bond is triggered by the bottom $\mathrm{Q}(\mathrm{T})$ (default probability) percentile of the simulated stock prices at the maturity date. In the present simulation, a risk-free interest rate is used to discount the cash flows. So, the new pricing model is considered to tally with the general pricing rule under martingale measure. The empirical results of the CEB and the XIG convertible bonds by the proposed method are compared with those obtained by the credit spreads method. It is also found that the theoretical prices calculated by the method proposed in the article fit the market prices well, especially, in the long run tendency.
\end{abstract}

\section{Introduction}

Convertible bonds are highly hybrid financial derivatives, which can be converted into the issuer's stock under some specified conditions. They are important refinancing tools for listed companies, and essential investment targets among hedge funds and other institutional investors. Due to their flexibility, convertible bonds are also well received by personal investors. The convertible bond is considerably more complex than the warrant, not only because it pays a periodic coupon, but also because it involves a dual option: on the one hand, the bond holder possesses the option to convert the bond into common stock at his or her discretion, and on the other hand, the firm possesses the option to call the bond for redemption, and the bondholder retaining the right to convert the bond or to redeem it. This call option is usually subject to some kind of restriction. The investor's optimal conversion strategy then depends on the firm's call strategy, and it appears at first sight that the optimal call strategies must depend on the inventor's conversion strategy, so that both optimal strategies must be solved for simultaneously.
Convertible bond valuation has been an important issue in both the academia and the industry. Pricing convertible securities was initiated by Ingersoll [1], who supposed that the bond value is a function solely of the firm value $\mathrm{A}$ and the time t, by Itô Lemma and the usual arbitrage arguments he got the Black-Sholes partial differential equation, the optimal strategies for call, conversion and put give the boundary conditions subject to which the B-S partial differential equation should be. For some special bonds (the discount bond, the consol bond) or in some special cases[1, 2], analytic solutions for these bond valuation could be obtained with the BlackSholes-Merton model.

Following Ingersoll's structural approach, Brennan and Schwartz $[3,4]$ were the first to apply the principles of the option pricing model to the convertible bond valuation. By optimal strategies for call and conversion, they got the boundary conditions of the convertible bond. By resorting to the finite differences method, Brennan and Schwartz got the numerical solution of the convertible bond value. The structural approach of the bond valuation developed by Ingersoll, Brennan, and Schwartz has two advantages at 
least. One advantage of the approach is that any contingent claim whose value can be written as a function solely of the market value of the firm and the remaining time to maturity $\tau, \mathrm{V}(\mathrm{A}, \tau)$, must satisfy the basic B-S partial differential equation; the various convertible securities can be described by the different boundary conditions. So, only needing to change the boundary conditions according to the indenture of the bond, we can get the solutions of the value of the various bonds through solving the B-S partial differential equation subject to the boundary conditions determined by the indenture of the bond. Another advantage of the approach is that it can measure the default risk by supposing that a default will occur only when the balloon payment cannot be met by all the assets of the firm; i.e., $A<B$, where $B$ is the face value of the bond plus the accrued interest at maturity. The default criterion can be demonstrated in the boundary conditions. So, the solutions of the convertible securities value include the default risk.

The structural approach of the bond valuation has a disadvantage; i.e., it is difficult to get the firm value. The firm value variable was soon replaced by the stock price for its simplicity in observation and measurement, which is the socalled reduced-form approach developed by McConnell and Schwartz [5]. The driving force of the valuation is changed to be the issuing firm stock price, which is also assumed to follow a stochastic process. This approach precludes the default risk, because there is no unequivocal way to link the stock price to a default event. In order to compensate the overestimate of the value in the reduced-form approach, McConnell and Schwartz used a risky interest rate as the discount rate. This method to measure the default risk is called the credit spreads (CS) method.

In the emerging China's convertible bond market, the convertible bonds are designed to have more complicated clauses compared with those of the mature markets, for example, stipulating the put provision, call provision subject to more restrictions, and the reset provisions. Because of the dual characters of the convertible bond, i.e., equity and bond, and moreover, the varieties of terms of Chinese convertible bonds, it is difficult to price the Chinese convertible bonds. Default risk is an important factor in convertible bond pricing. With some quasi-default events appearing recently in China's market, more attention to model the default risk is paid than before in China [6-8]. Because of the complexity, the convertible bond value can only be solved numerically in most practical cases. Monte Carlo simulation became widely used in convertible bond pricing [9-11].

As is known to all, it is important to describe the default risk for pricing the convertible bonds. On the whole, there exist two methods to measure the default risk. The first one is to use the credit spreads (CS), which is firstly used by McConell and Schwartz [5] to price convertible bonds. Following the work of McConell and Schwartz [5], Tsiveriotis and Fernandes [12] split a convertible bond into two components: a cash-only part, which was discounted by risky interest rate, and an equity part, which was discounted by risk-free interest rate. The second method is to use the default intensity (DI), which was introduced by Duffie and Singleton [13] to price corporate bonds. Then, Ayache et al. [14] applied the DI method to price convertible bonds; they used the default intensity to represent the risky interest rate; the convertible bond value can be gotten by solving the B-S partial differential equation, in which the defaultadjusted interest rate was contained, subject to the boundary conditions determined by the indenture of the convertible bond. The first method is more widely used for its simplicity and convenience than the second one. Early works $[5,12])$ priced the default risk of the convertible bond mainly by discounting at a higher risk-adjusted rate. However, as Batten et al. [15] pointed out, this approach is subject to criticism since credit risk spreads are neither constant over time nor constant along the yield curve.

Park, K. W. et al. [16] used the default intensity (DI) obtained from the transition probability matrix for rated firms to price the defaultable convertible bond. In the mature bonds markets, the DI can be obtained from the transition probability matrix for rated firms, which shows the probability of rating migration between the year and the next year. Up to now, there are no real default events occurring in the emerging bonds market of China, so, the transition probability matrix for rated firms did not show the default probability. So, Park's approach is not effective for pricing the Chinese convertible bonds. If the CS method is adopted to price the default risk, it is likely that the researchers are entangled by the otherwise great difference of the CS for different bonds, besides the above-mentioned criticism. The volatility is another difficulty for pricing Chinese convertible bonds. Issuing convertible bonds will affect the volatility of the underlying stock return and generally make the volatility of the underlying stock return decrease. The volatility calculated from the historical stock prices before issuing the convertible bond cannot be simply used to price the convertible bond. How to estimate the volatility of the stock after issuing the convertible bond, and how to estimate the DI more efficiently at least in theory? In the article, we will try to broaden the application of the Merton model [17] to solve these problems. Merton supposed that the firm value is comprised of the equity and the liability. The equity is considered as a call option on the firm value struck at the book value of the liability. From the Merton model, we can get the cumulative default probability and the volatility of the firm value after issuing the convertible bonds. To a certain extent, this volatility can be supposed to be the volatility of the underlying stock after issuing the bonds; this supposition should be reasonable. The further explanation will be given in the bottom of the next section.

The advantage of the present convertible bond pricing method lies in that the two important parameters, the longrun average volatility and the DI, can be directly calculated by the Merton model. In our approach, we price the default risk by immediately reducing cash flows to a fraction of the face value of the bond when a default event occurs; hence, the resulting cash flows are discounted at a risk-free rate. In this way, the general pricing rule under martingale measure is preserved in our pricing model.

This article is organized as follows. The second section discusses the convertible bond pricing model, in which we focus on dealing with the default risk and getting the 
default intensity and the long-term average volatility of the underlying stock price after issuing convertible bonds. The simulation design is given in the third section. The fourth section shows the results of the empirical research, including the comparison of the prices obtained by the DI method, and the CS method. Conclusions are presented in the last section.

\section{The Chinese Convertible Bond Pricing Model and the Parameters Estimation}

The Chinese convertible bonds are embedded with many options, such as the conversion option, call option, put option, and option to lower the conversion price. The valuation of the convertible bonds crucially depends on how the underlying stock price evolves over time and on the optimal stopping rules of both the investor and the issuer. It is assumed that the underlying stock price follows Brownian motion process with a constant volatility:

$$
\mathrm{d} S_{t}=\mathrm{rS}_{t} d t+\sigma S_{t} d Z
$$

where $S_{t}$ is the underlying stock price at the time $t, r$ is the risk-free interest rate, $\sigma$ is the volatility of the return of the stock, and $\mathrm{dZ}$ denotes the usual Wiener process.

Every moment before the maturity of the convertible bond, investors and issuers will gamble over the benefit. Investors will maximize the value of the convertible bonds, while the issuers will minimize the value of the convertible bonds from exercising the call option. Hence, at any time, the value of the convertible bond must not be less than its conversion value:

$$
\mathrm{V}\left(S_{t}, t\right) \geq m S_{t}
$$

where $\mathrm{V}\left(S_{t}, t\right)$ is the value of the convertible bond at the time $\mathrm{t}, \mathrm{m}$ is the conversion ratio, and $\mathrm{m} S_{t}$ is the immediate conversion value. If (2) does not hold, the investor would voluntarily convert bonds into stocks to make an immediate profit. The call provision of the Chinese convertible bonds emphasizes to force the bondholders to convert bonds into stocks immediately, for example, the call provision of the convertible bonds issued by China Everbrigh Bank Co., Ltd. (CEB): "In 30 consecutive trading days, the closing stock price is not less than $130 \%$ of conversion price in 15 trading days. The firm has the option to call the bond at the face value of the bond plus the current accrued interest." Because the call price, when the call condition is satisfied, is much lower than the conversion value, the firm should call the bonds, and if the bond is called, the bondholders must elect to convert the bonds into stocks. So, if the call condition is satisfied, the value of the convertible bond is the conversion value:

$$
\mathrm{V}\left(S_{t}, t\right)=\max \left\{K_{t}, m S_{t}\right\}=m S_{t}
$$

where $K_{t}$ is the call price at the time t. The investor will put the bond if the continuation value is less than the put price. So, the value of the convertible bond must not be less than the put price if the put condition is satisfied.

$$
\mathrm{V}\left(S_{t}, t\right) \geq P_{t}
$$

Suppose the asset of the firm consists of only the issuing convertible bonds and its underlying stocks. Suppose further that the indenture of the bond issue contains the following provisions and restrictions: (1) The firm promises to pay the balloon payment B, i.e., the face value of the bond plus the accrued interest, to the bondholders at maturity. (2) In the event this payment is not met, the firm will default on the bond. The firm value $\mathrm{A}(\mathrm{t})$ can be expressed as $\mathrm{A}(\mathrm{t})=$ $\mathrm{S}(\mathrm{t})+\mathrm{v}(\mathrm{t})$, where $\mathrm{S}(\mathrm{t})$ is the value at time $\mathrm{t}$ of the equity, $\mathrm{V}(\mathrm{t})$ is the value of the bond, and all the stock value and the firm value follow Brownian motion process with the same Wiener process, and the instantaneous returns on $\mathrm{S}$ and $\mathrm{A}$ are perfectly correlated [17, eq. (3.c)]. When $\mathrm{A}<\mathrm{B}$ at maturity, the firm will default on the bond. In order to consider the default risk in the convertible bond pricing, we introduce the exogenous variable cumulative default probability $\mathrm{Q}(\mathrm{T})$ and default intensity $\lambda(\mathrm{t})$. Given the cumulative default probability $\mathrm{Q}(\mathrm{T})$, it means that, at the maturity date, the bottom $\mathrm{Q}(\mathrm{T})$ percentile of the simulated firm values is equal to $\mathrm{B}$. we can get that the critical firm value $A_{t}^{\prime}$, i.e., equal to $\mathrm{B}$, be the lowest level below which the issuer will default on the bonds. Because there is a one-to-one correspondence between $S(t)$ and $A(t)$, and the stock value and the firm value follow Brownian motion process with the same Wiener process [17], we always can find a unique $S_{T}^{\prime}$ corresponding to $A_{T}^{\prime}$ by the bottom $\mathrm{Q}(\mathrm{T})$ percentile of the simulated stock prices at the maturity date. When the stock value is less than $S_{T}^{\prime}$, the firm will default on the bond.

In the Merton model, the equity is a call option on the firm value with the strike price equivalent to the liability book value. According to the call option model of the no-dividend asset, there exits the one-to-one correspondence between $S_{t}$ and the firm value $A_{t}$, and $S_{t}$ is the monotonically increased function of $A_{t}$. If we let $A_{t}^{\prime}$ be the lowest level below which the issuer will default on the bonds, a unique $S_{t}^{\prime}$ corresponding to $A_{t}^{\prime}$ always can be found at the time t. So, we can use variables $S_{t}$ and $A_{t}$ to describe equivalently the conditional default probability for $t \in[1,2, \ldots, T]$.

$$
\begin{aligned}
& \operatorname{Pr}\left(S_{t} \leq S_{t}^{\prime} \mid\left(S_{t-1}>S_{t-1}^{\prime}\right)\right) \\
& \quad=\operatorname{Pr}\left(A_{t} \leq A_{t}^{\prime} \mid A_{t-1}>A_{t-1}^{\prime}\right)
\end{aligned}
$$

Equation (5) guarantees that we can determine the default critical value $S_{t}^{\prime}$ by the same way as determining the default critical value $A_{t}^{\prime}$; i.e., $S_{t}^{\prime}$ is the bottom $\lambda$ (default intensity) percentile of the simulated stock prices.

Assuming a constant recovery ratio in the default event, the investor will receive a fraction, $\theta$, of the face value of the bond when the issuer defaults on the bond at time $t$ :

$$
\mathrm{V}\left(S_{t}, t\right)=\theta F, \quad \text { for } 0 \leq S_{t} \leq S_{t}^{\prime}
$$

where $\mathrm{F}$ is the face value of the bond and $S_{t}^{\prime}$ is the lowest stock price level at the time $t$ below which the issuer will default on the bond. 
At the maturity date, the payoff to the investor is given by the following:

$$
\begin{aligned}
\mathrm{V}\left(S_{T}, T\right) & =m S_{T} \quad \text { for } m S_{T} \geq B \\
& =B \quad \text { for } m S_{T}^{\prime}<m S_{T}<B, \\
& =\theta F \quad \text { for } 0 \leq m S_{T} \leq m S_{T}^{\prime}
\end{aligned}
$$

where the recovery ratio is assumed to be $0 \leq \theta \leq 1$.

In the credit risk analysis, should the risk-neutral default probability or the physical default probability be adopted? The answer to the question depends on the purpose of the study. The discounted present value of the cash flow needs to be calculated in pricing the convertible bonds; hence, one ineluctably employ the risk-neutral valuation theory. So, the default probability in the risk-neutral world should be adopted to price the credit derivatives. In estimation of the expected shortfall triggered by a default event by scenario analysis, the physical default probability should be adopted. According to the Merton model, at the maturity date, the stock value can be denoted as

$$
S_{T}=\max \left(A_{T}-B, 0\right)
$$

where $S_{T}, \mathrm{~B}$, and $A_{T}$ are the stock value at the maturity date, the balloon payment, and the firm asset value at the maturity date, respectively. We suppose that the stock value is the function of the firm value $\mathrm{A}$ and the remaining time to maturity $\tau, \mathrm{S}=\mathrm{S}(A, \tau)$. By the Ltô lemma and the usual arbitrage arguments, the stock price must satisfy the partial differential equation

$$
\frac{1}{2} \sigma^{2} A^{2} S_{A A}+r A S_{A}-r S-S_{\tau}=0
$$

where $\sigma$ is the volatility of the return of the stock, $\mathrm{r}$ is the risk-free rate of interest, and $\tau$ is the remaining time to maturity date. The solution of (9) subject to the boundary condition (8) is

$$
S_{0}=A_{0} N\left(d_{1}\right)-D e^{-r T} N\left(d_{2}\right)
$$

where

$$
d_{1}=\frac{\ln \left(A_{0} / D\right)+\left(r+\sigma_{A}^{2} / 2\right) T}{\sigma_{A} \sqrt{T}}
$$

and $d_{2}=d_{1}-\sigma_{A} \sqrt{T}$, and $\sigma_{A}$ is the volatility of the firm value, which is assumed to be constant for $\mathrm{t} \in[1,2, \ldots, T] . A_{0}$ is the current value of the firm asset. From Ito's Lemma, we get

$$
\sigma S_{0}=N\left(d_{1}\right) \sigma_{A} A_{0}
$$

where $\sigma$ is the volatility of the return of the stock before issuing the bonds.

The volatility of the return of the stock before issuing the bonds can be estimated by the historical stock prices. From (10) and (12), we can get $A_{0}$ and $\sigma_{A}$; then the cumulative default probability of the firm can be calculated by $\mathrm{N}\left(-d_{2}\right)$.
The convertible bond is a long-term security, so, a long-term average volatility should be adopted in pricing convertible bonds. The issuing of the convertible bonds will have an impact on the volatility of the underlying stock. The data of the underlying stock price after issuing the convertible bonds for pricing the convertible bond is generally insufficient or absent; hence, a long-term average volatility of the underlying stock after issuing the convertible bonds cannot be obtained from the historical data. So, we hope to find a theoretical method to get the long-term average volatility of the underlying stock after issuing the convertible bonds. The Chinese listed firm can prevail upon the investors to convert bonds by lowering the conversion price; in Chinese convertible bond market, nearly all convertible bonds have been converted into stocks. The firm's asset will become only equity. So, we use $\sigma_{A}$ of the firm value to replace the long-term average volatility of the underlying stock price after issuing the convertible bonds.

The cumulative default probability $\mathrm{Q}(t)$ can be expressed by the default intensity $\lambda(t)$

$$
\mathrm{Q}(t)=1-e^{-\int_{0}^{t} \lambda(\tau) d \tau}
$$

Assuming the default intensity is a constant, we can get

$$
\bar{\lambda}=-\frac{\ln (1-Q(T))}{T} .
$$

The cumulative default probability $\mathrm{N}\left(-d_{2}\right)$ is the probability that the firm cannot afford the balloon payment at the maturity. If the convertible bond is the only one senior debt, in theory, the firm may default only on the maturity date. So, in the convertible bond pricing, we only need to consider defaults that occur on the maturity date. In view of many factors that can result in defaults (including various term debts and adverse emergencies), these factors can result in the firm default on the bond prior to the maturity date. These factors also are among the driving forces that make the firm value change. In order to study the affecting factors of the convertible bond more overall, we still use the default intensity $\overline{\lambda(t)}$ to measure default risk prior to the maturity date, in spite of that call in question the rationality of doing so.

\section{Simulation Design}

Most of the Chinese firms stipulate the first put provisions: "if the investors do not exercise the put option when the put provision is firstly triggered, the investors will not be allowed to exercise the put option in the current year when the put provision is triggered again." The firm just needs to change the conversion price when the put provision is firstly triggered so as to promote the value of the convertible bond more than the put price. The investors will hold the convertible bonds instead of putting the convertible bond. The adjusted conversion price $X_{t}$ should satisfy

$$
\mathrm{P}=S_{t c} N\left(d_{1}\right)-F e^{-r(T-t)} N\left(d_{2}\right)+(F+I) e^{-r(T-t)}
$$


TABLE 1: Rules of optimal exercise decision in convertible bonds.

\begin{tabular}{lcc}
\hline Payoff & Condition & Decision \\
\hline$C_{t}$ & $V_{t}>C_{t}$ and $>m S_{t}$ & call \\
$\mathrm{m} S_{t}$ & $V_{t}>C_{t}$ and $C_{t}<m S_{t}$ & forced conversion \\
$\mathrm{m} S_{t}$ & $V_{t}<m S_{t}$ and $P_{t} \leq m S_{t}$ & voluntary conversion \\
0 & $V_{t}<C_{t}, V_{t}>m S_{t}$ and $V_{t}>P_{t}$ & continuation \\
$P_{t}$ & $P_{t}>V_{t}$ and $m S_{t} \leq P_{t}$ & Put \\
$\mathrm{B}$ & $\mathrm{mS}_{t}<B$ & redemption at maturity \\
$\theta \mathrm{F}$ & $\mathrm{S}_{\mathrm{t}}<\mathrm{S}_{\mathrm{t}}^{\prime}$ & default \\
\hline
\end{tabular}

where

$$
\begin{aligned}
& S_{t c}=\frac{100 S_{t}}{X_{t}} \\
& d_{1}=\frac{\ln \left(S_{t c} / F\right)+\left(r+\sigma_{A}^{2} / 2\right)(T-t)}{\sigma_{A} \sqrt{T-t}} \\
& d_{2}=d_{1}-\sigma_{A} \sqrt{T-t}
\end{aligned}
$$

and $\mathrm{P}$ and $\mathrm{I}$ are the put price and the accrued interest during $\mathrm{T}-\mathrm{t}$, respectively.

Including a default decision by the issuer, the optimal exercise decision of the investor and the issuer is summarized in Table 1. In our simulation, the convertible bond value is the expected discounted cash flow, which is estimated by the Longstaff-Schwartz (LS) Least Squares Monte Carlo (LSM) simulation method [18]. The optimal stopping rule can then be determined by the simultaneous optimal exercise strategies of both the investor and the issuer. For our simulation, we assume the discrete time by the day over the period with a finite time set $t \in[0,1,2 \ldots, T]$, where $t=0$ for today and $\mathrm{t}=\mathrm{T}$ for the maturity date. The basic framework of pricing Chinese convertible bonds by LSM is as follows.

(1) The duration of convertible bonds contains $T$ days, and the convertible bonds can only be exercised at the stipulated conversion period. Depending on the current stock price, we can get the $\mathrm{M}$ paths containing $\mathrm{T}$ days of the underlying stock price by Monte Carlo simulation.

(2) The defaulted group of the sample paths belongs to a bottom $\lambda$ percentile of the realized stock prices at each day. The issuer may default on the bond any time before or on the maturity, and we directly take into account the default risk in the present valuation. This is done by reducing the resulting cash flows immediately to a fraction $\theta$, of the face value of the bond when a default occurs in the simulated paths. By doing so, we adhere to the general pricing rule under martingale measure.

(3) When the put provisions have been triggered, the new conversion price is calculated by (15), and the value of the convertible bond is promoted equivalent to the put price.

(4) When the call provision has been triggered, no matter how big the conversion value is at that day, the convertible bonds will be exercised and terminated.

(5) By (7), the cash flows on the maturity date are obtained. In the other conversion time node, we choose the in-the-money option paths to estimate the continuation value by the Longstaff-Schwartz Least Squares simulation, which is accomplished by regressing the subsequent realized cash flows on a basis function of constants, $S$ and $S^{2}$. Comparing the continuation value with the exercise value, if the continuation value is bigger, the optimal stopping value remains the same; otherwise, the new stopping time and the new stopping value are obtained. For the out-of-the-money option paths, the convertible bonds will not be exercised, and one does not need to change the optimal stopping value.

(6) The convertible bond can be priced by discounting each cash flow back to time $t=0$ with the risk-free interest rate, and averaging over all paths.

\section{The Empirical Research}

To test the performance of our model, two convertible bonds issued by China Everbrigh Bank Co., Ltd. (CEB) with large market shares and Xiamen Itg Group Co., Ltd. (XIG) are randomly chosen for the empirical study. We adopt the data of the CEB and XIG convertible bonds at the issuing date, obtained from WIND database. The information of the two convertible bonds is in Table 2 .

For comparing with the CS method, we compute the theoretical prices of the two bonds using our simulation model and the CS method. It is well known to all that the convertible bond can be split into two components, a cashonly part and an equity part, for pricing the convertible bond [12]. In fact, the credit spreads of AAA-rated firm debts are only $1 \%$ in China's convertible market. For convenience, in the present calculation with the CS method, we use a risky interest rate to discount each cash flow without great influence on the price of the convertible bond. In the article, we use the mean yield of the defaultable enterprise debts in the same market as the risky interest rate. Before pricing, we first need to estimate the related parameters. The long-term mean volatility of the underlying stock, the equity value of the firm at issuing date, and the 6-year risk-free interest rate and the 6-year risky interest rate at the issuing date can be obtained from WIND database. By solving (10) and (12) with optimization method, we get the volatility of the firm asset value and the cumulative default probability of the firm. These 6 parameter values are given in Table 3 . Here, we have adopted the historical stock prices of 2 years for CEB and 5 years for XIG, respectively. The purpose for which we adopted the different term historical data is to lower the effect of the 2015 stock market crash on the pricing of the convertible bond. If a default occurs over the duration of convertible bonds, we choose an empirical constant recovery ratio of $20 \%$ for enterprise debts [19].

We simulate 50000 paths with 1440 time steps (240 days per year) before maturity to compute theoretical prices of the bonds. The simulated paths are generated by the risk-neutral dynamics of the stock return as (1). We also should note that the implied default probability of Merton model is the riskneutral. Hence, we can discount the cash flows that the riskneutral investor would receive over the period $t \in[1,2, \ldots, \mathrm{T}]$ at a risk-free interest rate $\mathrm{r}$, for pricing the convertible bond.

As the Chinese convertible bonds are generally set the conversion period, which is from the first day after six months 
TABLE 2: CEB and XIG convertible bonds.

\begin{tabular}{|c|c|c|}
\hline & CEB convertible bond & XIG convertible bond \\
\hline Issue date & 2017.3.31 & 2016.1.18 \\
\hline Time horizon & 6 & 6 \\
\hline Face value & 100 & 100 \\
\hline Coupon $(\%)$ & $0.2,0.5,1.0,1.5,1.8,2.0$ & $0.3,0.5,0.9,1.4,1.7,2.0$ \\
\hline Call value till maturity & 105 & 108 \\
\hline The first conversion price & 4.36 & 9.03 \\
\hline Change of conversion price & 2017.7.5, adjusted to 4.26 & 2016.6.21, adjusted to 8.93 \\
\hline Reset clause & $\begin{array}{c}\text { In } 30 \text { consecutive trading } \\
\text { days, the closing stock price is smaller } \\
\text { than } 80 \% \text { of conversion price in } 15 \\
\text { trading days. }\end{array}$ & $\begin{array}{c}\text { In } 30 \text { consecutive trading } \\
\text { days, the closing stock price is smaller } \\
\text { than } 90 \% \text { of conversion price in } 15 \\
\text { trading days. }\end{array}$ \\
\hline Call on condition & $\begin{array}{l}\text { In } 30 \text { consecutive trading days, the } \\
\text { closing stock price is not less than 130\% } \\
\text { of conversion price in } 15 \text { trading days. }\end{array}$ & $\begin{array}{l}\text { In } 30 \text { consecutive trading days, the } \\
\text { closing stock price is not less than 130\% } \\
\text { of conversion price in } 15 \text { trading days. }\end{array}$ \\
\hline Call value & Face value plus the accrued interest & Face value plus the accrued interest \\
\hline Put on condition & When the use of the capital is changed & $\begin{array}{l}\text { (1) When the use of the capital is changed } \\
\text { (2) In } 30 \text { consecutive trading days, the } \\
\text { closing stock price is less than } 70 \% \text { of } \\
\text { conversion price. }\end{array}$ \\
\hline Put value & Face value plus the accrued interest & Face value plus the accrued interest \\
\hline
\end{tabular}

TABLE 3: Parameters of the CEB and XIG convertible bonds. " $E_{0}$ " (hundred million) stands for the equity value of the firm at issuing date, " $\sigma_{s}$ " the long-term mean volatility of the underlying stock before issuing date, " $r$ " the 6-year risk-free interest rate at the issuing date, " $r y$ " the 6 -year risky interest rate at the issuing date, " $\sigma_{A}$ " the volatility of the firm asset value, and "Q" the cumulative default probability.

\begin{tabular}{ccccccc}
\hline & $E_{0}$ & $\sigma_{S}$ & $r$ & $r_{y}$ & $\sigma_{A}$ & Q \\
\hline CEB & 1918.5 & 0.2672 & 0.03158 & 0.04514 & 0.236 & 0.0007 \\
XIG & 106.5 & 0.4155 & 0.02780 & 0.03716 & 0.3447 & 0.0766 \\
\hline
\end{tabular}

of issuing bonds to the maturity date. So, in the present simulation, we assume a default may occur in this period for convenience. As seen in Table 3, the cumulative default probability of the CEB and XIG is 0.0007 and 0.0766 for 6 years, respectively. By (14), we can get the default intensity of $\mathrm{XIG} 6 \times 10^{-5}$ per day. In the present pricing of the convertible bonds with DI method, we consider that a default may occur only on the maturity date as well as prior to or on the maturity date. Because the cumulative default probability of CEB is too small, we just calculate the price of the CEB convertible bond with supposition that a default may occur only on the maturity date.

Figures 1 and 2 are the comparison of the theoretical prices and market prices of the two convertible bonds for 150 trading days. From Figures 1 and 2, three observations are noteworthy. Firstly, the theoretical prices calculated by CS method and DI method with supposition that a default may occur any time prior to or on the maturity date are very close for XIG convertible bond. The default probability of the CEB convertible bonds is so low that the calculated prices by assuming a default event may occur only on the maturity date, and on any time prior to or on the maturity it should be nearly

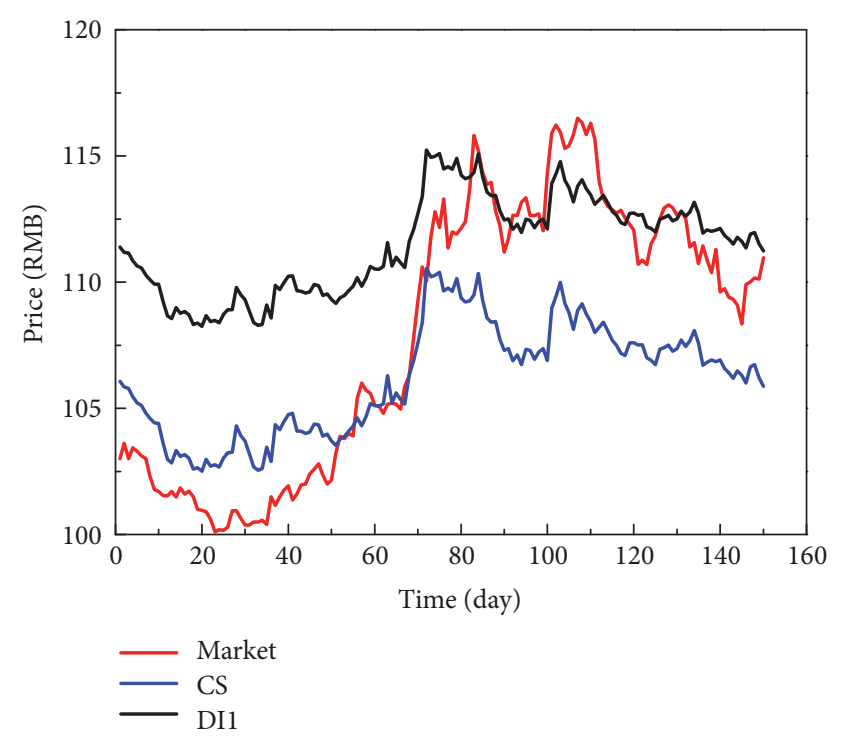

FIGURE 1: Comparison of the market prices and the theoretical prices of CEB convertible bond calculated by CS method and DI method with supposition that a default may occur only on the maturity date (DI1). 


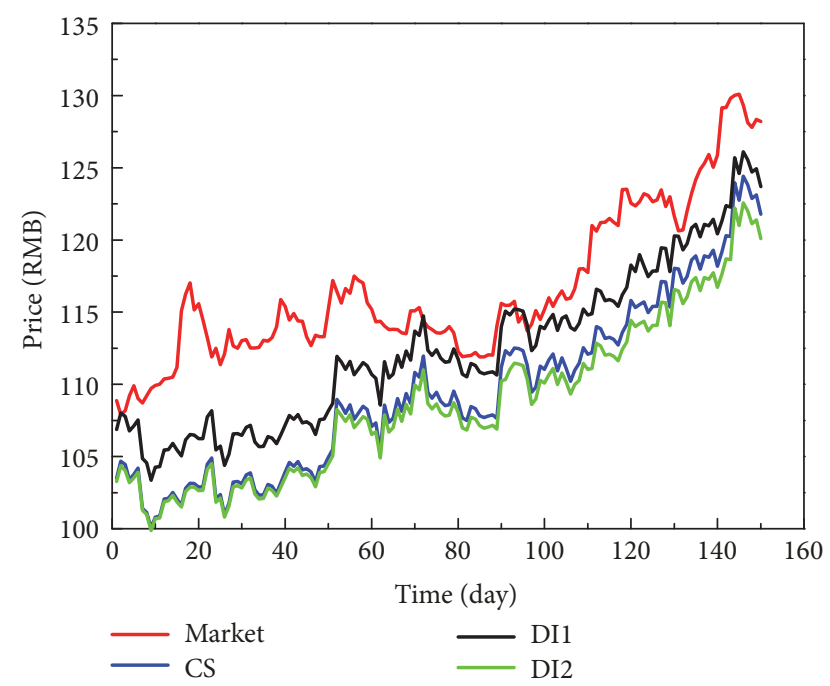

FIGURE 2: Comparison of the market prices and the theoretical prices of XIG convertible bond calculated by CS method and DI method with supposition that a default may occur only on the maturity date (DI1), and prior to or on the maturity (DI2).

the same. So, the theoretical price of the CEB convertible bond calculated by CS method is evidently smaller than that by the DI method. This is due to the fact that we adopt the mean risky interest rate of the defaultable enterprise debts in the same market to discount the cash flows. In fact, the convertible bond with the large market shares like CEB has a rather low default probability compared with the mean default probability of the market. So, the CS pricing method generally underestimates the price of the convertible bond with the large market shares like CEB. This is a shortcoming of the CS method. Secondly, with the application of the same default probability, the price estimated by supposition that a default may occur only on the maturity date is evidently larger than that by supposition that a default may occur any time prior to or on the maturity. By checking the simulated cash flows, we find that an otherwise defaulted firm may continue to survive and pays out a higher sum to the investor before the maturity. However, the investor loses the chance of a higher sum being paid out when a default is allowed to occur in any time. Lastly, we can see that the tendencies of the market prices and the theoretical prices calculated with supposition that a default may occur only on the maturity date as in Figures 1 and 2 fit well in the long run.

We introduce the variable $\mathrm{AD}$ to describe the absolute deviation of the theoretical price from the market price, which is given in the following formula:

$$
A D_{t}=\frac{\left|V_{t}-\overline{V_{t}}\right|}{\overline{V_{t}}}
$$

The mean absolute deviation (MAD) is used to describe the integral result of the theoretical models:

$$
\mathrm{MAD}=\frac{1}{150} \sum_{t=1}^{150} A D_{t}
$$

TABLE 4: The mean absolute deviation (MAD) of the theoretical prices of the CEB and XIG convertible bonds calculated by the CS method and the DI method with supposition that a default may occur only on the maturity date (DI1), and prior to or on the maturity (DI2).

\begin{tabular}{lccc}
\hline & CS & DI1 & DI2 \\
\hline CEB & $2.97 \%$ & $3.86 \%$ & \\
XIG & $6.07 \%$ & $3.58 \%$ & $6.75 \%$ \\
\hline
\end{tabular}

TABLE 5: The standard deviation (STD) of the theoretical prices of the CEB and XIG convertible bonds calculated the CS method and the DI method with supposition that a default may occur only on the maturity date (DI1), and prior to or on the maturity (DI2).

\begin{tabular}{lccc}
\hline & CS & DI1 & DI2 \\
\hline CEB & 0.0040 & 0.0037 & \\
XIG & 0.0073 & 0.0070 & 0.0106 \\
\hline
\end{tabular}

Table 4 reports the MAD of the CEB and XIG convertible bonds calculated by different methods. As can be seen there, the MADs of CEB and XIG convertible bonds calculated by CS and DI are all within 7\%. The theoretical prices obtained by CS and DI, on the whole, can reflect market price. The DI method with supposition that a default may occur only on the maturity matches the market best, especially in the long run tendency. So, we can use our pricing framework to forecast market price of convertible bond and make investment decision.

The standard errors (SEs) of the calculated prices of the convertible bonds by the CS method and the DI method at the first trading day are given in Table 5. The SEs for DI method with supposition that a default may occur only on the maturity are little less than those of the CS method price.

\section{Conclusion}

In this article, we have presented a new way to price the convertible bond by LSM, in which the credit risk is measured by DI. The key idea in our model is to get important parameters, such as the long-run average volatility and the DI directly from Merton model, which avoids the difficulty from the data lack of the emerging market, especially, up to now, no effective method estimating the long-run average volatility of the underlying stock after issuing convertible bonds. In the present empirical study, the theoretical prices fit the market very well. So, our model including the method to get the DI and the long-run average volatility is proved to be effective. The present simulation has shown that the convertible bond price is quite sensitive to the rule on the default decision time, allowing an earlier default decision which will lower the convertible bond price.

\section{Data Availability}

The data used to support the findings of this study are supplied by wind database and are also available from the corresponding author upon request. 


\section{Conflicts of Interest}

The authors declare that they have no conflicts of interest.
[19] R. d. Cheng and J. R. Lu, "A monte carlo method of integrated risk measurement for defaultable zero-coupon bonds," Journal of Management Sciences in China, vol. 15, no. 4, pp. 88-97, 2012.

\section{References}

[1] J. E. Ingersoll Jr., "A contingent-claims valuation of convertible securities," Journal of Financial Economics, vol. 4, no. 3, pp. 289321, 1977.

[2] C. M. Lewis, "Convertible debt: Valuation and conversion in complex capital structures," Journal of Banking \& Finance, vol. 15, no. 3, pp. 665-682, 1991.

[3] M. J. Brennan and E. S. Schwartz, "Convertible bonds: valuation and optimal strategies for call and conversion," The Journal of Finance, vol. 32, no. 5, pp. 1699-1715, 1977.

[4] M. J. Brennan and E. S. Schwartz, "Analyzing convertible bonds," Journal of Financial and Quantitative Analysis, vol. 15, no. 4, pp. 907-929, 1980.

[5] J. J. McConnell and E. S. Schwartz, "LYON Taming," The Journal of Finance, vol. 41, no. 3, pp. 561-576, 1986.

[6] C. Fan, X. Luo, and Q. Wu, "Stochastic volatility vs. jump diffusions: Evidence from the Chinese convertible bond market," International Review of Economics \& Finance, vol. 49, pp. 1-16, 2017.

[7] X. Hu and H. Mao, "Empirical study on the financial characteristics of chinese companies issuing convertible bonds," International Journal of Business and Management, vol. 4, no. 6, pp. 59-64, 2009.

[8] L. $\mathrm{Lu}$ and W. Xu, "A simple and efficient two-factor willow tree method for convertible bond pricing with stochastic interest rate and default risk," The Journal of Derivatives, vol. 25, no. 1, pp. 37-54, 2017.

[9] M. Ammann, A. Kind, and C. Wilde, "Simulation-based pricing of convertible bonds," Journal of Empirical Finance, vol. 15, no. 2, pp. 310-331, 2008.

[10] S. Crépey and A. Rahal, "Pricing convertible bonds with call protection," The Journal of Computational Finance, vol. 15, no. 2, pp. 37-75, 2011.

[11] R. Schöftner, "On the estimation of credit exposures using regression-based Monte Carlo simulation," The Journal of Credit Risk, vol. 4, no. 4, pp. 37-62, 2008.

[12] K. Tsiveriotis and C. Fernandes, "Valuing convertible bonds with credit risk," The Journal of Fixed Income, vol. 8, no. 2, pp. 95-102, 1998.

[13] D. Duffie and K. J. Singleton, "Modeling term structures of defaultable bonds," Review of Financial Studies , vol. 12, no. 4, pp. 687-720, 1999.

[14] E. Ayache, P. A. Forsyth, and K. R. Vetzal, "Valuation of convertible bonds with credit risk," The Journal of Derivatives, vol. 11, no. 1, pp. 9-29, 2003.

[15] J. A. Batten, K. L.-H. Khaw, and M. R. Young, "Convertible bond pricing models," Journal of Economic Surveys, vol. 28, no. 5, pp. 775-803, 2014.

[16] K. Park, M. Jung, and S. Lee, "Pricing a defaultable convertible bond by simulation," Korean Journal of Financial Studies, vol. 46, no. 4, pp. 947-965, 2017.

[17] R. C. Merton, "On the pricing of corporate debt: the risk structure of interest rates," The Journal of Finance, vol. 29, no. 2, pp. 449-470, 1974.

[18] F. A. Longstaff and E. S. Schwartz, "Valuing American options by simulation: a simple least-squares approach," Review of Financial Studies, vol. 14, no. 1, pp. 113-147, 2001. 


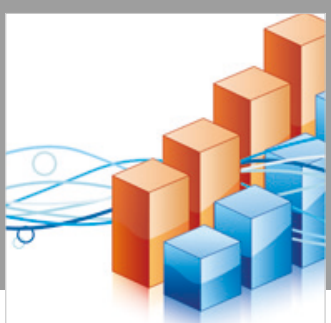

Advances in

Operations Research

\section{-n-m}
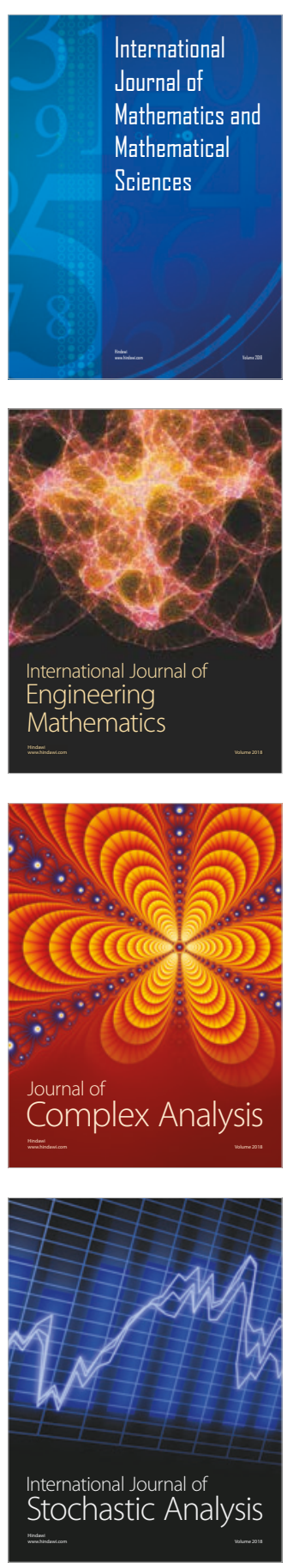
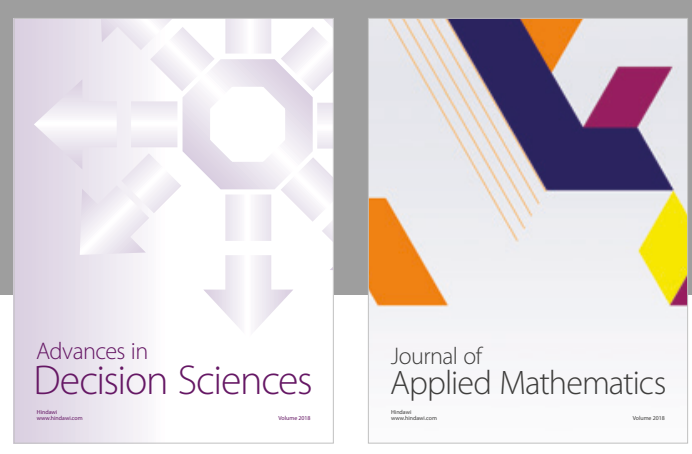

Journal of

Applied Mathematics
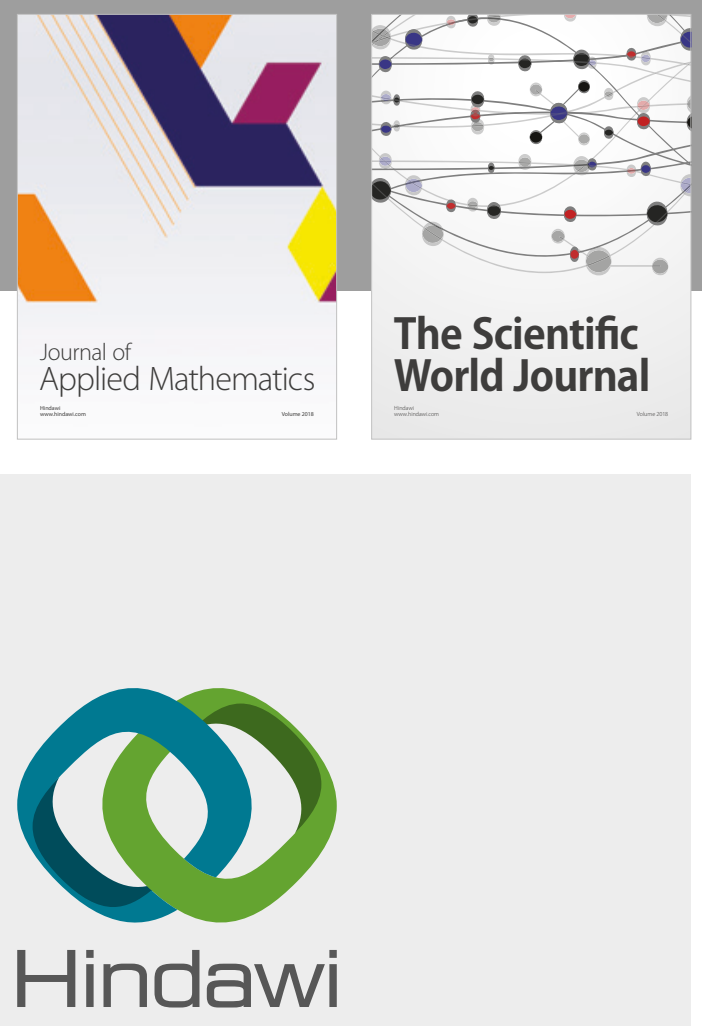

Submit your manuscripts at

www.hindawi.com

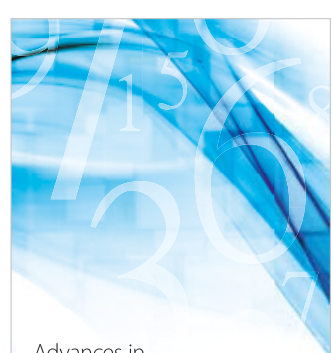

Advances in
Numerical Analysis
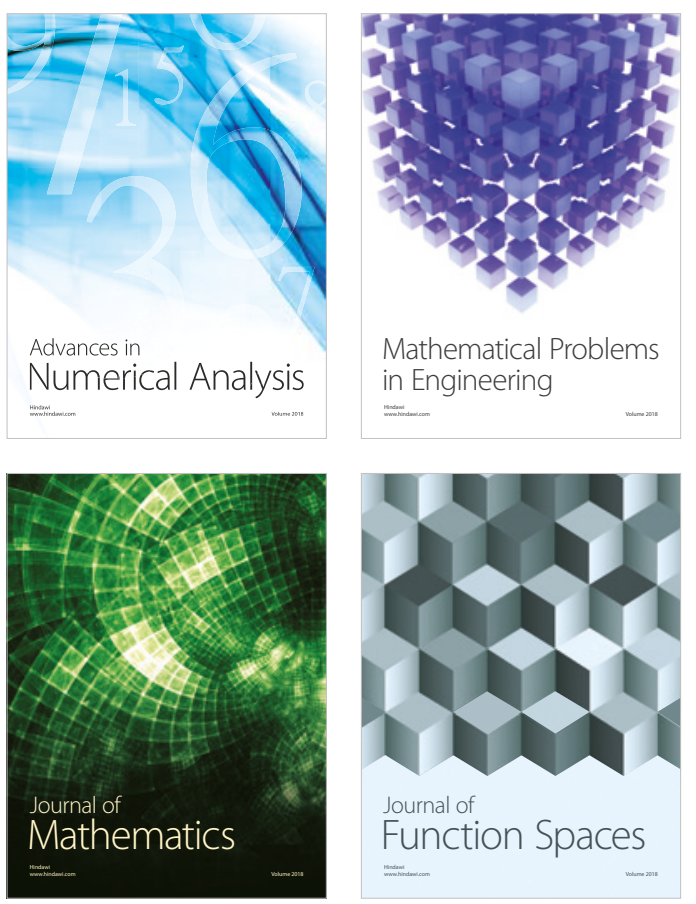

Mathematical Problems in Engineering

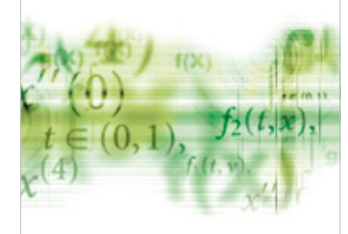

International Journal of

Differential Equations

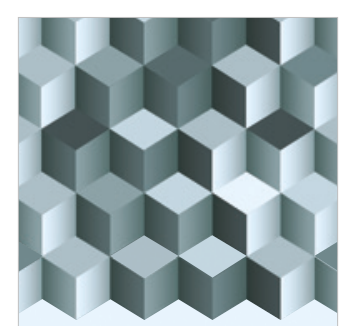

Journal of

Function Spaces

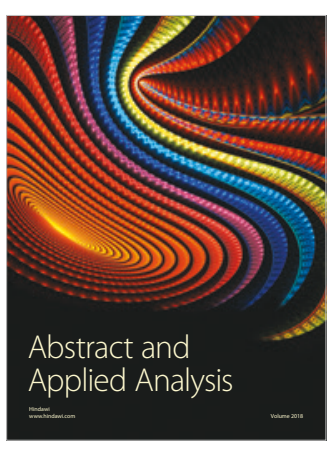

The Scientific

World Journal

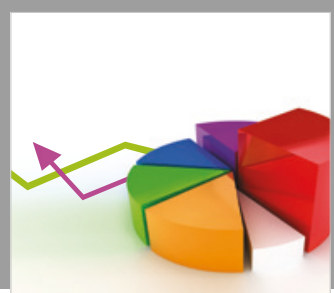

Journal of

Probability and Statistics
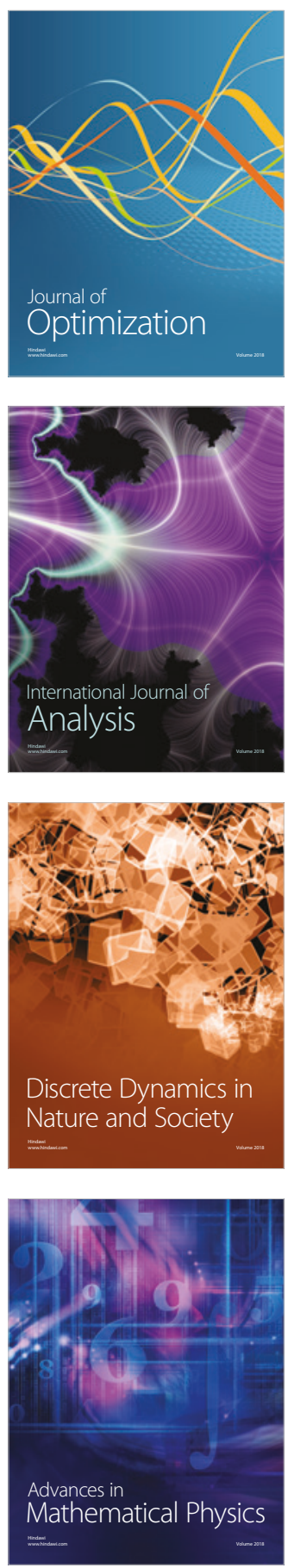